\title{
Hazardous Drinkers and Drug Users in HMO Primary Care: Prevalence, Medical Conditions and Costs
}

Number 5, June 2006

\section{POLICY PERSPECTIVE}

ONGOING SCREENING IN

PRIMARY CARE SETTINGS

FOR HAZARDOUS DRINKING

AND DRUG USE CAN BE

HELPFUL IN REDUCING

HEALTH RISKS, HEALTH CARE

COSTS AND HEALTH CARE

UTILIZATION RATES. POLICY-

MAKERS CAN PLAY A ROLE

IN ENCOURAGING HEALTH

CARE PROFESSIONALS TO

CONDUCT SUCH SCREENINGS

BY SUPPORTING POLICIES

THAT PROVIDE RESOURCES

AND TRAINING TO THOSE

WHO CARRY THEM OUT.

\section{Research Highlight}

\section{Background}

| azardous drinking (such as frequent heavy drinking) is "alcohol consumption which confers the risk of physical and/or psychological harm." Screening for hazardous drinking and drug use in primary care settings is recommended to identify individuals with these problem behaviors. Also, interventions for hazardous drinking can be cost-effective due to reductions in medical costs. Few studies have specifically looked at the effects of screening on drug use, but severe drug problems are associated with higher health care costs.

In their study, "Hazardous Drinkers and Drug Users in HMO Primary Care: Prevalence, Medical Conditions and Costs," Jennifer Mertens and colleagues use primary care settings to examine associations between these problems and medical conditions and investigate the costs of health care for hazardous drinkers and drug use. In the study, 1,419 patients were screened for hazardous drinking and drug use. Of these patients, 95 individuals who were positive for hazardous drinking and drug use $^{3}$ agreed to participate. This group's medical records were compared to 13,347 individuals who used the care facilities at the same times and were patients at the clinic in the prior year, yet were not screened.

\section{Findings}

One in $\mathbf{1 0}$ primary care patients is a hazardous drinker and/or drug user. Specifically, 7.5 percent are hazardous drinkers while 3.2 percent are hazardous drug users.

Hazardous drinkers and/or drug users have a higher prevalence of various psychiatric and medication conditions than other primary care patients. These conditions include: chronic obstructive pulmonary disease (COPD), hypertension, pneumonia, injury and overdoses, congestive heart failure, depression, anxiety and major psychoses.

Reported Medical and Psychological Conditions among Hazardous Drinkers and/or Drug Users (HDDUs) and Non-Hazardous Drinkers and/or Drug Users

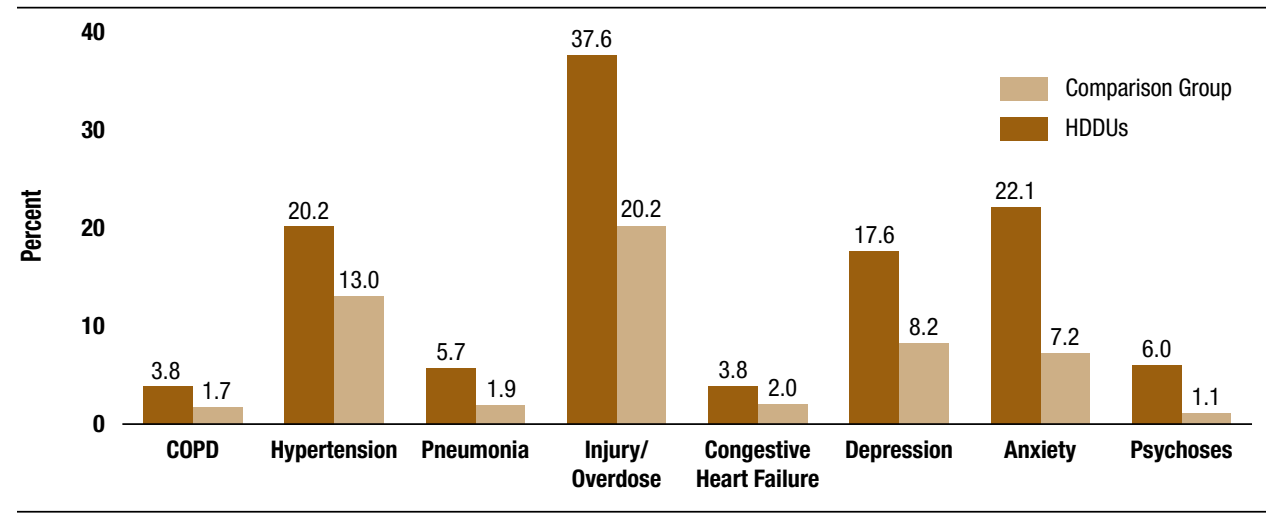


Hazardous drinkers and/or drug users have more primary care and psychiatry visits than other patients. Primary care costs were higher for this group as well. Hazardous drinkers and/or drug users without psychiatric symptoms had lower utilization rates and pharmaceutical costs than those with psychiatric symptoms.

-Deanna Lewis Deanna Lewis is a Robert Wood Johnson Foundation/Rutgers Policy Fellow.

1 Saunders JB, Aasland OG, Amundsen A, Grant M "Alcohol Consumption and Related Problems Among Primary Health Care Patients: WHO Collaborative Project on Early Detection of Persons With Harmful Alcohol Consumption-I." Addiction 88(3): 349-362, 1993.

2 Mertens JR, Weisner C, Ray GT, Fireman B and Walsh K. "Hazardous Drinkers and Drug Users in HMO Primary Care: Prevalence, Medical Conditions and Costs." Alcobolism: Clinical and Experimental Research, 29(6): 989-997, 2005.

3 A hazardous drinker might be someone who drinks four or more times a week, consumes three drinks on a typical day of drinking, and has had a relative express concern about his/her drinking. The researchers used this tool (the AUDIT) to assess hazardous drinking: Online at $b$ ttp://wwere.alcoholscreening.org. The tool is recommended for primary care use by the United States Preventive Services Task Force. (Babor TF, de la Fuente JR, Saunders J, Grant M. AUDIT. The Alcohol Use Disorders Identification Test: Guidelines for Use in Primary Health Care. World Health Organization Programme on Substance Abuse. 1992. 